\title{
The geodetic detection of the variable load impact on the earth-filled structure
}

\author{
Przemysław Kuras $^{1}$ (D) $\cdot$ Łukasz Ortyl $^{1}$ (D) $\cdot$ Tomasz Owerko $^{1}$ (D) $\cdot$ Aleksandra Borecka $^{2}$ (D)
}

Received: 2 January 2020 / Accepted: 29 May 2020 / Published online: 29 June 2020

(C) The Author(s) 2020

\begin{abstract}
This article concerns the evaluation of displacement monitoring referred to the earth-filled flood embankment using surveying and radar measurement techniques. The results allow to reveal the embankment reaction to the external loads. The results of longterm geodetic monitoring clearly imply the dominance of displacements directed outside for points located on the embankment slopes. The displacement values were also referred to the course of the changing water level representing a flood wave, in order to point out the mutual relationship between them. Horizontal displacements indicate that earth-filled embankments may behave to some extent like elastic structures. For the experiment, which covered determining the embankment response to the varying water level, ground-based radar interferometry was used as an alternative measurement technique. This selection was justified primarily by the submillimeter accuracy of the displacement measurement. However, the research required overcoming a few limitations, among which the atmosphere variability is the most important. This was taken into account by measuring the current atmospheric conditions and correcting the results by atmospheric delay. For the time intervals in which it was possible to compare surveying and radar measurement techniques, the displacement values were analyzed and referred to the current structure load resulting from the variable water level. A sizable number of the observations allow to perceive some tendencies, even if the displacement values were at the measurement uncertainty level. The movement trend is consistent for both methods. This was evidenced particularly by the compatibility of the considerable displacements detected for the points located in the area of presumed embankment failure. Moreover, the differences are within the limits of agreements determined on the basis of the BlandAltman plot, which means that these two measurement methods could be used interchangeably.
\end{abstract}

Keywords Radar interferometry $\cdot$ Geodetic monitoring $\cdot$ Earth-filled structure $\cdot$ Flood embankment

\section{Introduction}

Flood embankments were known in ancient times, and they are one of the most common and simplest forms of protection against flooding. However, their effectiveness will never be $100 \%$, as there is a risk of their damage, interruption, overflow of water, or the occurrence of other adverse phenomena. The main purpose of testing flood embankments is to obtain

Przemysław Kuras

kuras@agh.edu.pl

1 Department of Engineering Surveying and Civil Engineering, AGH University of Science and Technology, 30 Mickiewicza Av., 30-059 Krakow, Poland

2 Department of Hydrogeology and Engineering Geology, AGH University of Science and Technology, 30 Mickiewicza Av., 30-059 Krakow, Poland specific data (topographic, geometric, hydraulic, morphological, geotechnical, geological, etc.) that can be applied to assess their condition, performance, or structure design of the entire embankment system (for new embankments or for modification of the existing ones).

The phenomenon of flood occurs when, for example, water overflows onto a normally dry land. The effect of flooding traveling along a river is called a flood wave, which has its velocity and depth (amplitude) continuously changing with time and distance. It is possible to predict quite accurately the movement of a flood wave along the river, which is the basis for creating early flood warning systems (Mujumdar 2001). Flood embankments are erected to protect the surrounding area against the passage of a flood wave, but then they are most exposed to failures.

A numerical analysis of flood embankment displacement is presented by Moelmann et al. (Moellmann et al. 2011). For a transient seepage analysis, a typical slip surface is shown on 
the example of the Elbe River. Modeled displacements are particularly apparent on the downstream side of the embankment. Similar conclusions are shown by Gikas and Sakellariou (2008) for an earth dam on the example of the Mornos dam. For the selected analyzed cases, the spatial distribution of the anticipated risk of failure is asymmetric, with changes appearing especially on the downstream side of the dam. Hydrological problems also apply to natural earth objects. Ferrigno et al. (2017) present landslide activity caused by heavy rainfall that threatened existing infrastructure. The behavior of the earthflow was controlled by GB-InSAR monitoring and observational methods.

Geotechnical monitoring allows to determine changes taking place in a structure as well as their sources and mutual dependencies. Geotechnical key parameters (such as inclination, stress, or temperature) are usually measured using various types of sensors. However, geodetic methods are irreplaceable to determine the location of a measuring point (and also its changes). According to the ISO Standard No. 18674-1 ( 2015), Section 4.4, "for the support, evaluation, and control of geotechnical measurements, reference shall be made to geodetic measurements if applicable."

Various measurement techniques, especially geodetic ones, are important for supplementing geotechnical monitoring. Pirotti et al. (2015) present the state of the art of geomatics technologies applied to landslides and flooding and the associated natural hazards related to the dynamics of hydrological variability. Among the geodetic methods they mention are as follows: Global Navigation Satellite Systems (GNSS), photogrammetry, synthetic aperture radar (SAR), remote sensing, and laser scanning. An example of geodetic monitoring applied to study landslide activity is presented by Ferhat et al. (2017). The monitoring network, composed of precise leveling and repeated GNSS benchmarks, as well as piezometers and inclinometers, was founded for the investigation of the water circulation within the landslide. Another example of infrastructure monitoring, based on geodetic surveys and geotechnical instruments, is presented by Serrano-Juan et al. (2016). It includes leveling, differential GNSS, robotic total stations, and the geotechnical techniques comprising of pendulums, inclinometers, extensometers, piezometers, gyros, and optical fiber-based techniques. In addition, groundbased synthetic aperture radar (GB-SAR) is installed in to acquire measurements in $2 \mathrm{D}$ covering areas of up to a few square kilometers in a single acquisition.

Displacements are the common quantity determined in the monitoring of water dams. Jafari et al. (2015) present a comprehensive study in which they indicate the relationship between subsidence of an earth dam and water level in a reservoir. In addition to surveying instruments, soil extensometers and settlement plates were used in the monitoring system. In turn, Dardanelli and Pipitone (2017) present horizontal displacement monitoring using classic surveying observations and GNSS networks. They indicate that the differences in displacement values determined by these techniques are not greater than $8 \mathrm{~mm}$; however, in this case the displacements do not exceed the uncertainty level of their determination. Nevertheless, in a situation of small displacements a large number of observations are helpful in identifying trends occurring on the structure (Pipitone et al. 2018).

In deformation monitoring, especially for engineering structures, the use of interferometric radar is a good complement to geodetic observations in several aspects. In the field of structure dynamics testing, the possibility of simultaneous observation of many points is a significant advantage (Piniotis et al. 2016). In addition, a much higher sampling frequency, exceeding $100 \mathrm{~Hz}$, is unreachable in the field of geodetic monitoring (Lienhart et al. 2017). However, the ability to conduct reliable radar observations requires high reflection intensity, which depends on the type of surface being observed, and often, especially when observing natural objects, requires the use of corner reflectors. It is also problematic to limit displacement observations to only one direction, radial to the radar position, and then geodetic observations provide significant support (Owerko et al. 2012). On the other hand, when studying landslide dynamics, surface observations carried out using the GB-SAR technique can be supplemented with classic measurements (automated total stations, GNSS) to ensure the proper embedding of radar measurements in the reference system (Castagnetti et al. 2013). Radar observations can also be a supplement to a landslide early warning system. Intrieri et al. (2012) use the IBIS-L system for this purpose along with wire extensometers, which provide point-like information of a single fracture, whereas the GB-SAR system records the global movement of a continuous surface.

\section{The subject of the research}

The purpose of this research is the evaluation of the application of radar and geodetic measurements in the monitoring of earth-filled structures. This task was accomplished by a field experiment, which included simultaneous observation of the earth structure surface using radar and surveying techniques, and then verifying the compliance of the determined displacements.

The research was conducted on the fragment of $4.5-\mathrm{m}$ high flood embankments (Fig. 1), consisting of two parallel sections. They were connected to each other, creating a small reservoir with a maximum capacity of about $9500 \mathrm{~m}^{3}$, in which it is possible to change the water level. The soil profile of levee and its subsoil for the fragment that was covered by the comparative study is presented in Fig. 2. During the research, the embankments were subjected to variable water levels reflecting the passage of a typical river flood wave. 


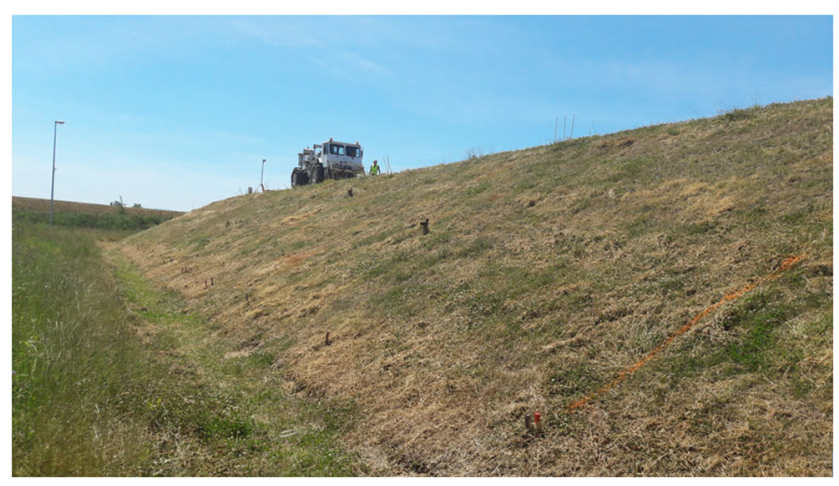

Fig. 1 A view of the flood embankment selected for the experiment

For the needs of the research works, an appropriate network of reference points and survey markers has been designed and established. The observation network was adapted to the planned geodetic observations using precise instruments: digital level, total station, and the IBIS-L interferometric radar. Due to the type of conducted experiments, it was particularly important to determine displacements in the eastwest direction, which is perpendicular to the embankments axis. Based on previous numerical calculations (Stanisz et al. 2017), this is the direction of the expected movements.

The basis of the network was reference points (Fig. 3a), which were designed as reinforced concrete pillars providing forced centering. Each pillar was founded $2 \mathrm{~m}$ below the ground level and connected to the reinforced concrete slab. The above ground part of the pillar was encased with a casing pipe, which was filled with thermally insulating material. On the other hand, the properly designed survey markers (Fig. $3 b$ ), which served as the measuring points, were arranged on the surface of the observed embankment. All markers consist of a steel rod with a length of $1.5 \mathrm{~m}$ set in the ground, finished at the top with a concrete stub. A steel profile was embedded in the concrete stub, allowing for the permanent installation of the benchmark and both prism and radar reflectors, which can be rotated in any direction without changing the center's position. The markers were installed on the slopes and foreground of the embankment.

The designed and finally established angular-linear observation network consists of 5 observation pillars and 48 survey markers. Considering the number of unknowns, the network has approximately 140 redundant observations. A detailed network design is presented by Kuras et al. (2018).

The stability of the reference points was checked every time on the basis of a 4-parameter conformal transformation between the original and current coordinate system, assigned to a given measurement epoch. In the course of the calculations, it was found that all reference points remained stable. Their residual displacements was equal approx. $0.4 \div 0.5 \mathrm{~mm}$ (RMSE), while the accuracy of determining these values, calculated as the transformation error, was at the level of $0.3 \div 0.4 \mathrm{~mm}$.

\section{The geodetic observations}

The geodetic observations were carried out for two purposes. The first, preliminary one was carried out to assess the possibility of conducting long-term monitoring, in order to determine the influence of atmospheric factors (e.g., soil freezing), vehicles moving on the embankment body or the vestigial subsidence of the newly built embankment. The second purpose was to check the behavior of the embankment as a result

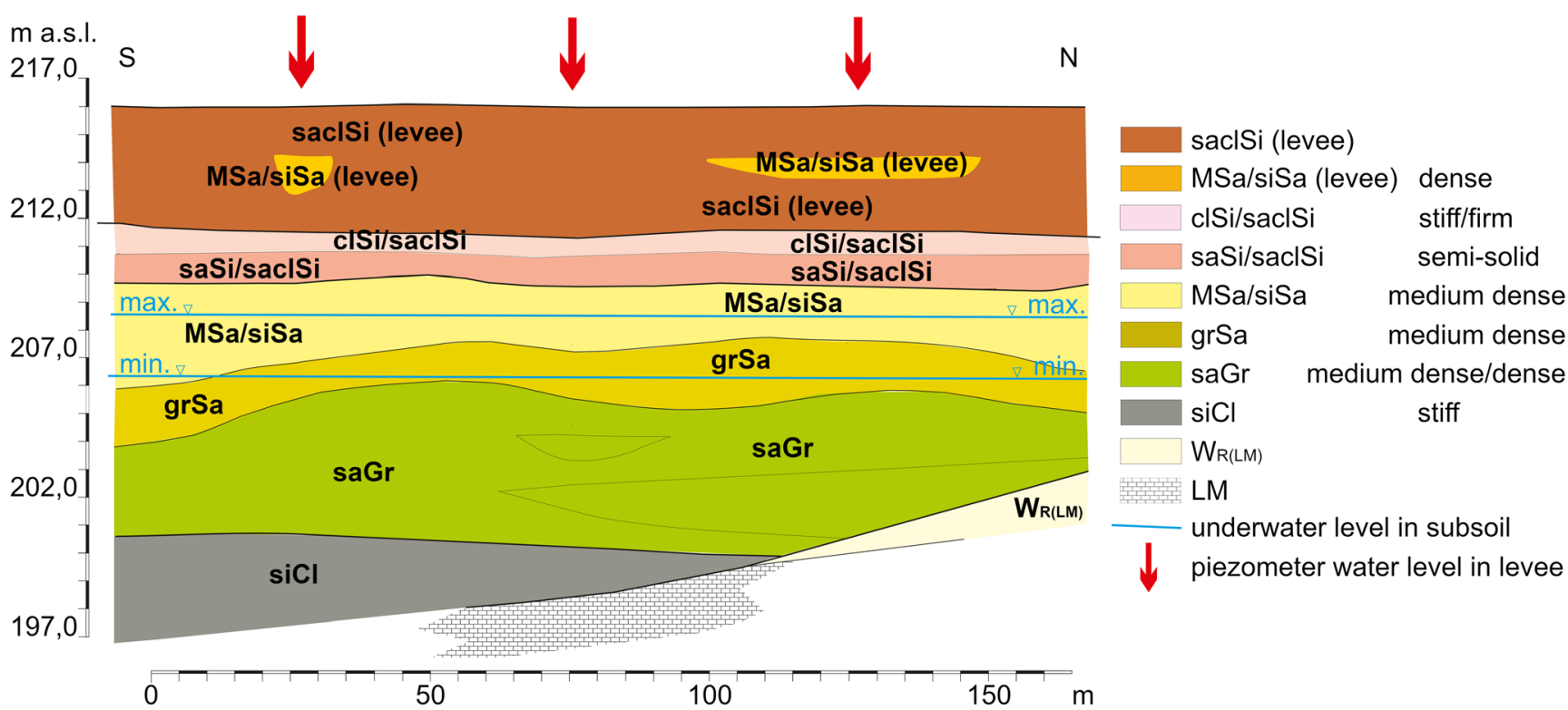

Fig. 2 A soil profile for levee and its subsoil. In addition to soil types, the maximum and minimum groundwater levels during research were indicated, as well as the location of piezometers for measuring water levels 
Fig. 3 The elements of a geodetic network: (a) the pillar constituting a reference point and (b) a survey marker equipped with a radar reflector and surveying prism
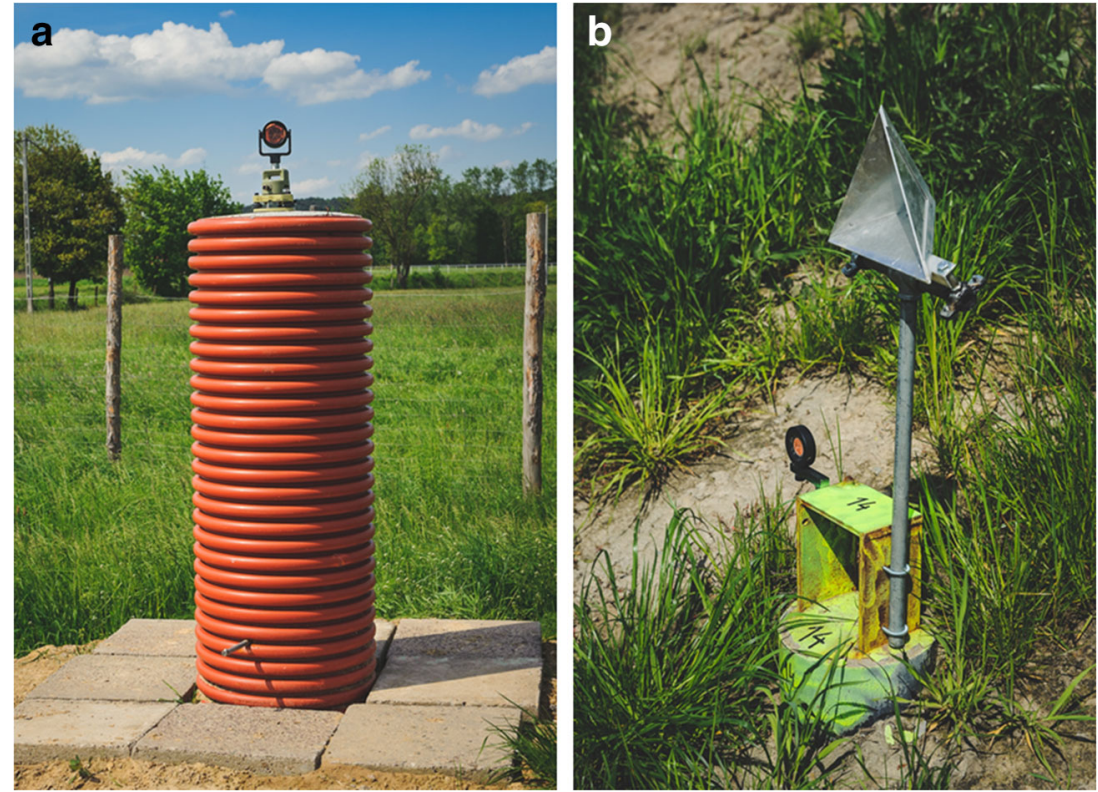

of the changing water level and, ultimately, a comparison with the results of the radar observations.

Figure 4 shows the displacement values averaged for points situated at the same height and determined 11 and 18 months after the initial measurement. Only the east-west (E-W) component of the displacements was analyzed, while it is perpendicular to the axis of both embankments and it was the expected direction of the displacements. The results clearly indicate the dominance of the displacements directed outside for the points located on the embankment. The points on the crest and on the foreground do not show significant movements (visible vectors may result from measurement errors). The results are summarized in Table 1.

The second purpose of the surveying was achieved based on the observations carried out during the variable water level, whose course is shown in Fig. 5 in blue. The " $X$ " symbols indicate the days when the geodetic network was measured. They determine the intervals of the embankment's displacements. The period of radar measurement, which is the subject of the further part of the article, is also marked.

Due to the low values of the calculated displacements, often at the level of their determination errors, only the E-W components of the displacements were selected for further calculations, as they were expected in the numerical analyses. In addition, points were divided into groups according to the height of their foundation. Averaging the values of the displacements (Table 2) allows to perceive some tendencies (Fig. 6).

In the interval 1 the water level increased and the embankment was soaking for a few days. All of the observed points then showed movement outside of the embankment by an average of $1.2 \mathrm{~mm}$. Then, in the interval 2, when the water level went down, the opposite tendency of the points located on the crest was visible. The remaining points did not show significant (more than $0.5 \mathrm{~mm}$ ) changes in location. In short intervals 3 and 4 , when the water level went up twice, the displacement values are small ( $0.3 \mathrm{~mm}$ on average); however, there is a tendency of the movement directed outside for the points located on the embankment. Finally, in a relatively long interval 5, when the embankment could dry up, the points located on its body clearly moved inside the embankment (1.6 $\mathrm{mm}$ on average), returning more or less to their position before the measurements had started. It is illustrated by the values marked as $\Sigma$ in Table 2, which are smaller than $0.5 \mathrm{~mm}$ in most cases. This return tendency is not shown by the points on the foreground, for which a $1.0-1.5-\mathrm{mm}$ displacement outside the embankment can be found.

On the basis of the above analysis, the relation between embankment soaking and the directions of its movement can be noticed. During the periods of increasing the water level and for some time after its decrease, when the levee was still saturated with water, movements directed outside were

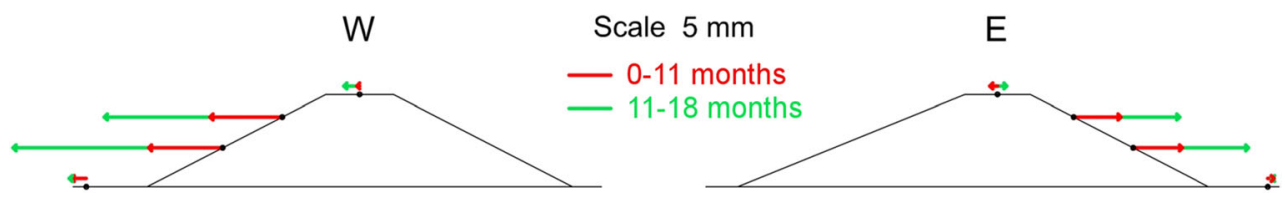

Fig. 4 The average long-term E-W displacements for groups of points situated at the same height. Displacements in the period of 11 months from the beginning are presented in red, whereas these values for the interval 11-18 months age are given in green 
Table 1 The average long-term displacements $(D)$ in the east-west $(\mathrm{E}-\mathrm{W})$ direction and their diversity expressed as spread $(S)$ for the groups of points situated at the same height on the western and eastern embankment

\begin{tabular}{|c|c|c|c|c|c|c|}
\hline \multirow[t]{2}{*}{ Group of points } & \multicolumn{3}{|c|}{ Embankment W } & \multicolumn{3}{|c|}{ Embankment E } \\
\hline & No. of pts. & $\begin{array}{l}D_{0-11} \\
D_{11-18} \\
(\mathrm{~mm})\end{array}$ & $\begin{array}{l}S_{D 0-11} \\
S_{D 11-18} \\
(\mathrm{~mm})\end{array}$ & No. of pts. & $\begin{array}{l}D_{0-11} \\
D_{11-18} \\
(\mathrm{~mm})\end{array}$ & $\begin{array}{l}S_{D 0-11} \\
S_{D 11-18} \\
(\mathrm{~mm})\end{array}$ \\
\hline \multirow[t]{2}{*}{ Crest } & 7 & -0.3 & 6.4 & 7 & -0.9 & 10.9 \\
\hline & & -1.5 & 5.1 & & 2.0 & 4.8 \\
\hline \multirow[t]{2}{*}{$2 / 3$ of $H(3.0 \mathrm{~m})$} & 4 & -8.7 & 6.2 & 4 & 5.7 & 13.0 \\
\hline & & -12.7 & 2.5 & & 7.0 & 6.0 \\
\hline \multirow[t]{2}{*}{$1 / 3$ of $H(1.5 \mathrm{~m})$} & 7 & -8.9 & 9.7 & 7 & 5.9 & 16.1 \\
\hline & & -16.3 & 16.2 & & 7.9 & 7.6 \\
\hline \multirow[t]{2}{*}{ Foreground } & 2 & -1.8 & 2.3 & 3 & 0.8 & 0.7 \\
\hline & & -0.2 & 0.6 & & -0.3 & 2.3 \\
\hline
\end{tabular}

revealed. On the other hand, the following long period of drying caused movement in the opposite direction.

In addition to determining horizontal displacements, the occurrence of embankment settlement due to changing water level was also checked. Precise leveling of all measuring points included in the geodetic network was carried out. The maximum height error obtained in a single adjustment does not exceed $0.2 \mathrm{~mm}$. Measurements were made five times, alternately by low and high water levels. The average settlement values for the measuring points located on the levee are summarized in Table 3 (divided into crest and slope).

The distribution of settlements presented on histograms (Fig. 7) and average values of settlements of points on the levee (Table 3) do not indicate a relationship with the water level. The predominance of negative values may presumably indicate long-term subsidence associated with seasonal changes, i.e., insolation and drying of the embankment.

\section{The choice of radar technique}

The classic observation techniques discussed above are used in particular to determine long-term displacements in the external reference system. Such observations are discontinuous, but in the discussed case of the research, lasting over a dozen of days, in which the phenomena will appear slowly, it is reasonable to use them to determine the displacements. However, the results presented above indicate that the displacement values are on the level of the accuracy of the measurement method. Hence, it was advisable to perform the observations using a different technology. Ground-based radar interferometry (GB-SAR) was used as an alternative technique. The IBIS-L unit from IDS was used for the tests. The parameters of this device are as follows: central frequency $f_{\mathrm{c}}=$ 17.2 GHz (Ku band), bandwidth $B=300 \mathrm{MHz}$, range resolution $\Delta R=0.5 \mathrm{~m}$, angular resolution $\Delta \theta=4.3 \mathrm{mrad}=0.25^{\circ}$, and azimuth resolution $\Delta A=1.09 \mathrm{~m}$ (at $250 \mathrm{~m}$ distance).

The GBSAR technique allows to meet three main requirements relevant to the observation of the earth-filled embankment, which are as follows: the discretization of the observed surface, continuous observation of the occurring phenomena, and submillimeter accuracy of the displacement measurement.

\section{Discretization of the observed surface}

For this type of structures it is necessary to simultaneously observe many points located on the surface. Discretization

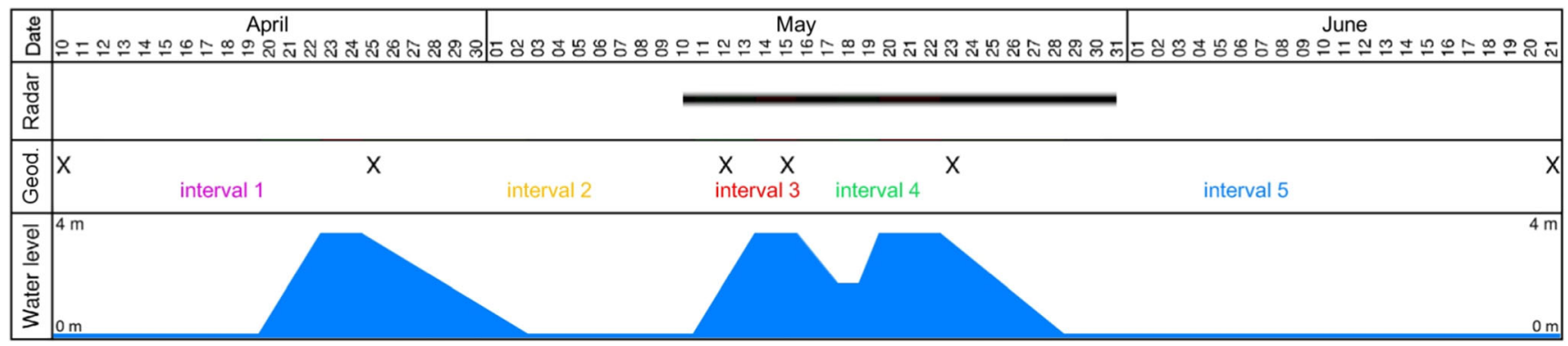

Fig. 5 The timeline of the measurements. The second row presents the duration of the radar measurement, while the " $\mathrm{X}$ " symbols in the third row represent the surveying observations and determine the five intervals of the experiment. At the bottom, the water level that was affecting the embankment is colored in blue 
Table 2 The average E-W displacements determined during five intervals of water level changes for the groups of points situated at the same height on the western and eastern embankment (Kuras et al. 2018)

\begin{tabular}{lllllll}
\hline \multirow{2}{*}{ Group of points } & \multicolumn{7}{l}{ Embankment W (mm) } & & & \\
& Int. 1 & Int. 2 & Int. 3 & Int. 4 & Int. 5 & $\boldsymbol{\Sigma}$ \\
Crest & -1.0 & 1.0 & -0.6 & -0.5 & 0.8 & -0.2 \\
$2 / 3$ of $\mathrm{H}(3.0 \mathrm{~m})$ & -1.7 & -0.1 & -0.4 & 0.0 & 3.1 & 0.9 \\
$1 / 3$ of $\mathrm{H}(1.5 \mathrm{~m})$ & -0.9 & -0.3 & -0.1 & -0.8 & 2.5 & 0.4 \\
Foreground & -0.5 & -0.4 & -0.5 & 0.4 & -0.3 & -1.3 \\
& Embankment E $(\mathbf{m m})$ & & & \\
& Int. 1 & Int. 2 & Int. 3 & Int. 4 & Int. 5 & $\boldsymbol{\Sigma}$ \\
Crest & 1.3 & -1.8 & 0.7 & 0.4 & -0.7 & -0.1 \\
$2 / 3$ of $\mathrm{H}(3.0 \mathrm{~m})$ & 1.3 & -0.3 & 0.5 & -0.1 & -1.8 & -0.4 \\
$1 / 3$ of $\mathrm{H}(1.5 \mathrm{~m})$ & 0.9 & -0.1 & 0.2 & 0.1 & -0.8 & 0.3 \\
Foreground & 1.2 & -0.3 & -0.4 & 0.0 & 0.8 & 1.4 \\
\hline
\end{tabular}

of the observed surface to the form of many points is based on two parameters of the radar system - range resolution $\Delta R$ and azimuth resolution $\Delta A$. In Fig. 8 a graphic interpretation of these values is shown. A single pixel can be observed if there is a radar wave reflecting object within the space bounded by a cuboid with a base $\Delta A \times \Delta R$-in this case: the embankment surface.

Images obtained by GB-SAR have limitations resulting from radar measurement parameters (Pieraccini et al. 2001). The range resolution $\Delta R$ depends on the frequency bandwidth $B$, and for the SFCW (stepped-frequency continuous wave) radar it is given by formula:

$\Delta R=\frac{c}{2 B}$

where $c$ is the speed of light.

During the research, the maximum range resolution obtainable by the IBIS-L was set. It equals $\Delta R=0.5 \mathrm{~m}$, which results from the possibility of adopting the value $B=300 \mathrm{MHz}$ for observation. This means that on the outer slope of the embankment, which has a slant length of $10 \mathrm{~m}$, it is possible to observe about 20 pixels in the direction of the $y$ axis. This value is approximate, because the effective value of $\Delta R^{\prime}$ depends on the location of the radar relative to the observed object (Kuras and Ortyl 2014).
Table 3 Average settlements of the measuring points located on the levee during the experiment

\begin{tabular}{lllll}
\hline & $10 \mathrm{Apr}-$ & $25 \mathrm{Apr}^{-}$ & $\begin{array}{l}\text { 11 May- } \\
\text { 22 May }\end{array}$ & $\begin{array}{l}\text { 22 May- } \\
\text { 5 Jun }\end{array}$ \\
\hline Levee & -0.14 & -0.34 & -0.14 & -0.42 \\
- Crest & -0.17 & -0.48 & -0.06 & -0.37 \\
- Slope & -0.12 & -0.21 & -0.20 & -0.45 \\
\hline
\end{tabular}

The $\Delta R$ value does not depend on the distance from the radar to the object and is constant throughout the observed space. However, the azimuth resolution $\Delta A$ decreases with the distance $R$ to the target according to

$\Delta A=R \cdot \Delta \theta$

where $\Delta \theta$ represents the angular resolution.

Angular resolution, in turn, depends on the parameters of the linear scanner used in the GB-SAR system, according to the equations (Pieraccini et al. 2001):

$L \geq \frac{c}{2 f_{\mathrm{c}} \Delta \theta}$

$\Delta x \leq \frac{c}{4 f_{\mathrm{c}}}$

where $L$ is the length of the linear scanner rail (max. $2 \mathrm{~m}), f_{\mathrm{c}}$ is the central frequency (17.2 GHz for IBIS-L system), and $\Delta x$ is the single step of the linear scanner.

During the research, the maximum angular resolution obtainable by the IBIS-L radar system was adopted, which is $\Delta \theta=0.25^{\circ}$. This means that the observed surface of the embankment, which lies within the distance interval of $67 \mathrm{~m}<R$ $<85 \mathrm{~m}$ from the radar, will be covered by pixels with a transverse dimension of $0.29 \mathrm{~m}<\Delta A<0.37 \mathrm{~m}$.

\section{Continuous observation}

During the experiment, the observed embankment should soak up with water and dry out, and the effect of these phenomena is the subject of observation. For this reason, continuous observation is required, regardless of the atmospheric and lighting conditions.

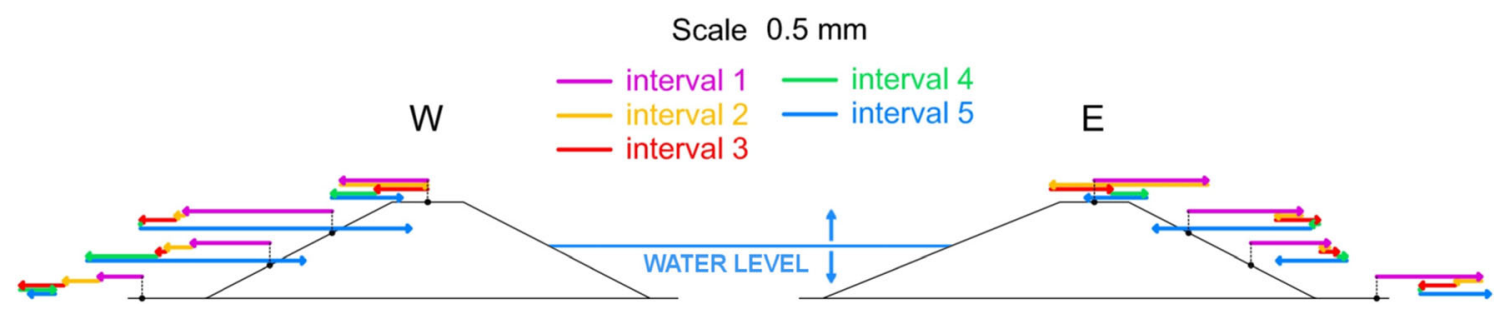

Fig. 6 The average E-W displacements determined during water level changes for the groups of points situated at the same height for consecutive intervals assigned with color arrows 
Fig. 7 Histograms of settlements of the measuring points located on the levee during water level change (horizontal axis: settlements $(\mathrm{mm})$, vertical axis: number of points)
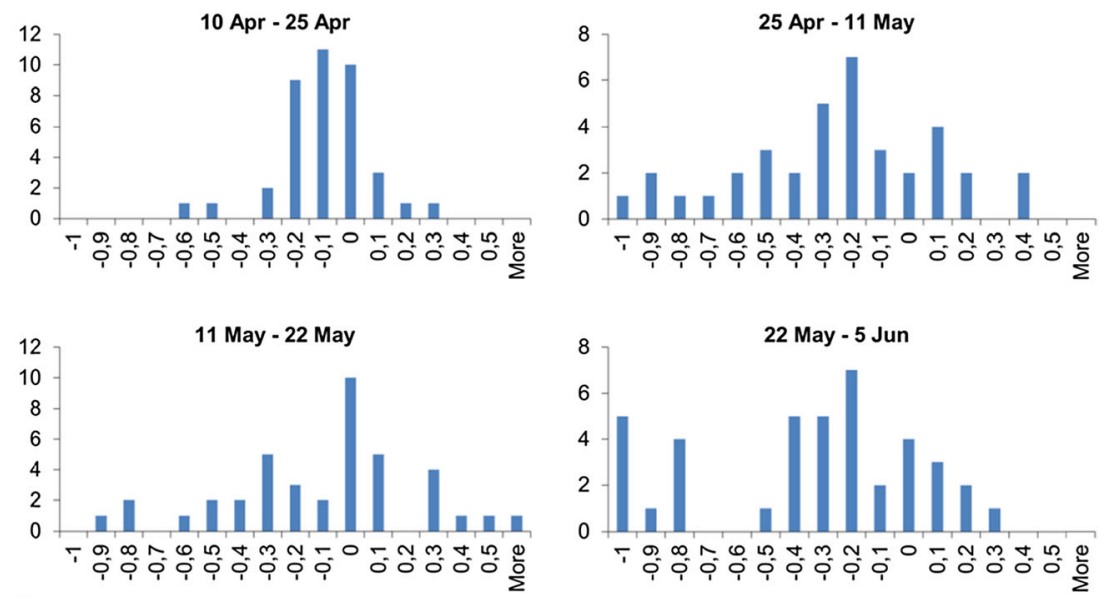

When choosing the time gap between subsequent measurements, the dynamics of the phenomenon is of particular importance. If the object's movement in the period between subsequent imaging exceeds the value of $\pm \lambda / 4$, which means \pm $4.4 \mathrm{~mm}$ for the IBIS-L system, then the displacement will be determined ambiguously due to the cycle slip effect.

Although in this experiment the deformations of this order were not predicted, the minimum imaging time for the IBIS-L system was adopted due to the possibility of dynamic changes in the atmospheric conditions, in particular humidity. It means about $10 \mathrm{~min}$ for a single radar imaging.

\section{Displacement accuracy}

The accuracy of displacement measurement using radar techniques is the subject of many studies. The values of nominal precision provided by the manufacturers of various terrestrial interferometric systems were collected by Monserrat et al. (2014) and cover the range from 0.01 to $4 \mathrm{~mm}$. In the planned experiment, the expected displacements are on the order of $1 \mathrm{~mm}$, which results from numerical simulations (Stanisz et al. 2017). Therefore, it is necessary to analyze what conditions have to be met to determine the displacement reliably, and provide the measurement error of less than $1 \mathrm{~mm}$.

According to Di Pasquale et al. (2013) the accuracy of displacement $(D)$ depends only on the accuracy of the phase $(\varphi)$ measurement, while

$D=\frac{\lambda}{4 \pi} \Delta \varphi$

where $\lambda$ represents the radar wavelength, which equals $17.4 \mathrm{~mm}$ for the IBIS-L system.

Radar systems have an accuracy of phase measurements at the level of approximately $30^{\circ}$ for a mildly decorrelated scene, which corresponds to an accuracy of $\lambda / 24$ in displacement measurements (Di Pasquale et al. 2013). For the IBIS-L system, this means a displacement measurement accuracy of $0.7 \mathrm{~mm}$. This value significantly depends on the properties of the observed scene and decreases, e.g., for a surface covered by vegetation (due to the interferometric coherence losses). However, for structures (especially steel and concrete) this source of decorrelation is not present and displacements can be determined with better accuracy.

Accuracy tests conducted under favorable conditions have shown that the displacement measurement accuracy
Fig. 8 The projection of the range resolution $(\Delta R)$ and azimuth resolution $(\triangle A)$ on the embankment surface. The local radar coordinate system is marked

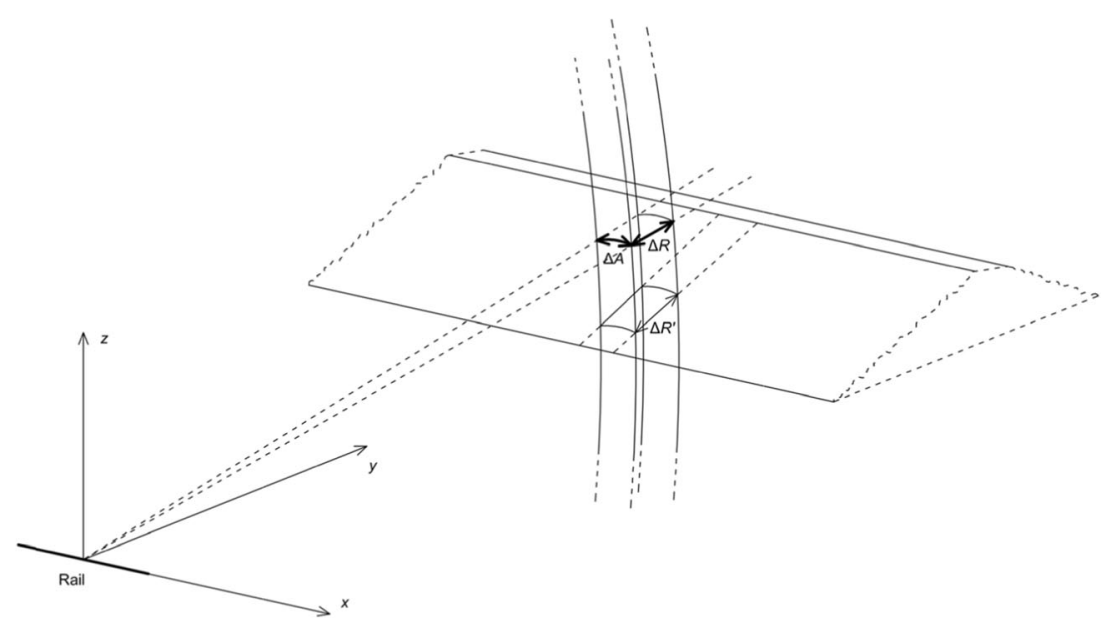


Fig. 9 The scope of the embankment covered by radar measurement and the location of the reflectors

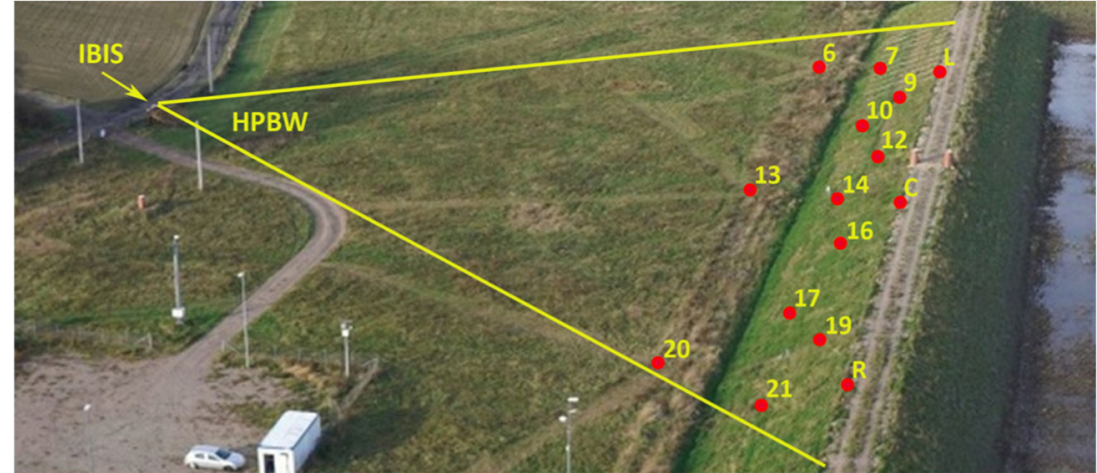

reaches values from 0.005 to $0.15 \mathrm{~mm}$ (Gentile and Bernardini 2010; Gocał et al. 2013; Xing et al. 2014; Qi et al. 2015). In actual field conditions the accuracy decreases to 0.3-2.0 mm (Bozzano et al. 2011; Ferrigno et al. 2017; Frukacz and Wieser 2017), especially for large distances. Nevertheless, in the presented experiment the accuracy was expected at the level of $0.2 \div 0.3 \mathrm{~mm}$ due to

- the relatively short distance (approximately $100 \mathrm{~m}$ ),

- the use of radar reflectors that significantly reduce the signal decorrelation, and

- the acquisition of weather station data for further atmospheric correction.

\section{Experiment limitations}

Measurements of actual objects require the consideration of field restrictions, which often do not occur at the stage of laboratory tests. The following three limitations should be taken into account for radar measurements: limited observation space, vegetation, and atmosphere variability.

\section{Limited observation space}

Field conditions limit the space for observation. This factor is important since the location of the radar in relation to the structure affects the size of the area that can be observed. The HPBW (half-power beamwidth) angle is particularly important, and it depends on the type of radar antennas used for observation. It means the angle between two directions, for which the radiation power is half as low (i.e. $-3 \mathrm{~dB}$ in a logarithmic scale) as than for the direction of the maximum radiation (Kuras and Ortyl 2014). Outside the HPBW angle range, the signal sent becomes weaker and weaker, which consequently decreases the accuracy of the displacement measurement.

In the experiment, wide-angle antennas were used, for which the azimuth HPBW is $38^{\circ}$. The IBIS-L radar station was designed considering this value and the length of the embankment section that was included in the experiment (Fig. 9). In addition, the displacement component that will be observed by the radar is also important when selecting a position. In the presented case, the location of the radar is optimal from the point of view of the expected direction of displacement, which is perpendicular to the longitudinal axis of the embankment. In addition, the
Fig. 10 The SNR map for the radar imaging expressed in the local radar coordinate system. Adjusting the position of the radar reflectors into the local SNR maxima is additionally presented

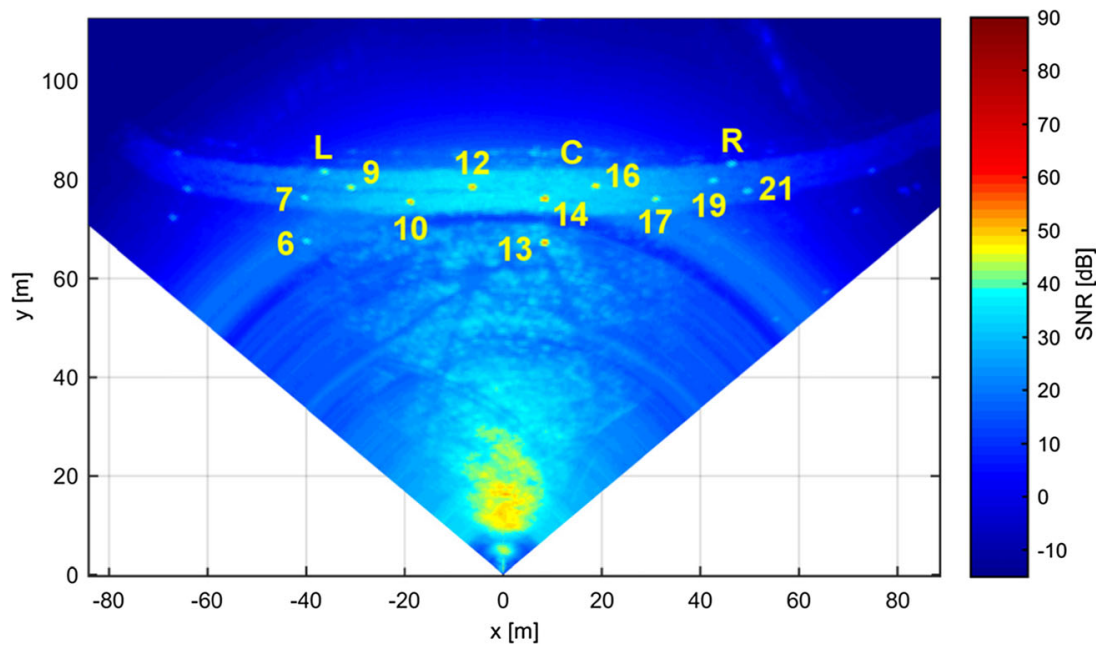


Fig. 11 The changes in atmospheric conditions (temperature, atmospheric pressure, and humidity) during the observation and the changes in the measured distance caused by them, calculated with an empirical formula

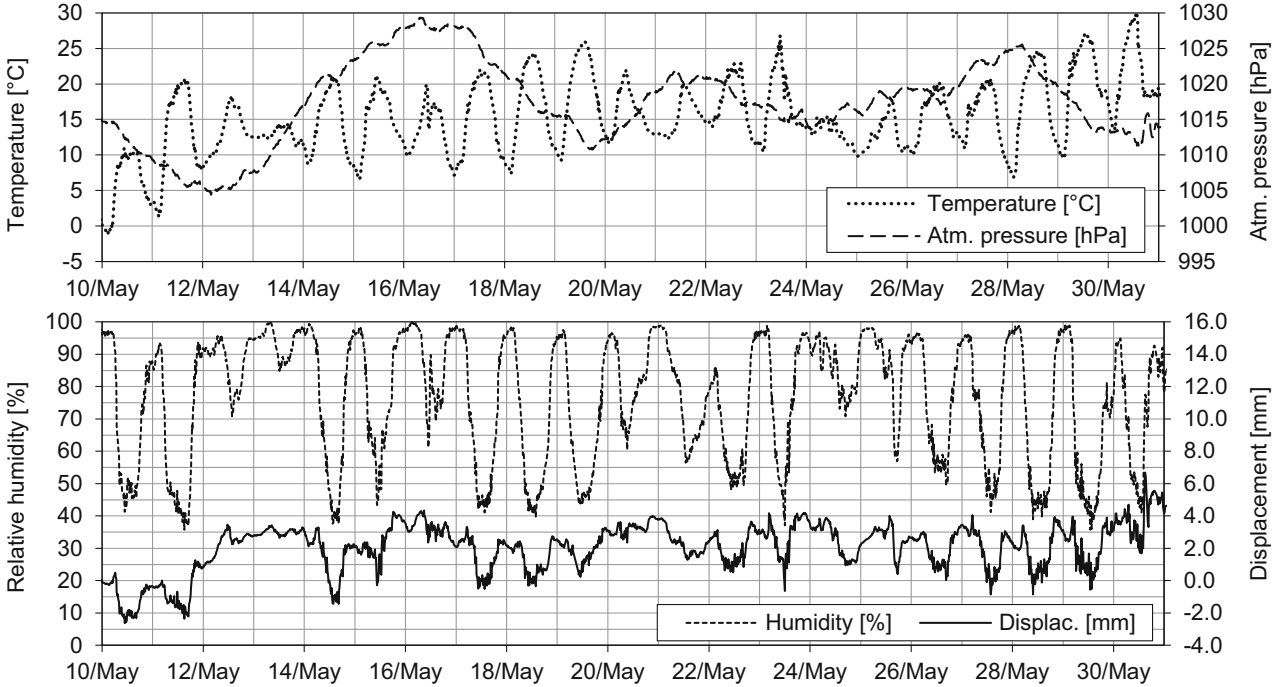

radar station was set approximately $2.5 \mathrm{~m}$ above the ground to reduce noise from vegetation.

\section{Vegetation}

Covering with vegetation (grass) is typical for river embankment. As stated in "Displacement accuracy," vegetation has an adverse impact on the accuracy of displacement observation using the radar technique. In order to detect the actual displacement of the embankment structure, radar reflectors were mounted on it (Fig. 3b).

Figure 10 presents the distribution of the SNR values for the scene observed by the radar. At the distance of about $80 \mathrm{~m}$ from the radar unit, reflections from the surface of the tested embankment are visible. Among them, it is possible to indicate the pixels corresponding to the location of the radar reflectors; however, the points marked as L, C, and R are temporary radar reflectors mounted on tripods on the crest.

For all of the identified radar reflectors the values of SNR, calculated as the ratio between the mean value and the standard deviation of the signal amplitude, are higher than $15 \mathrm{~dB}$. Given the relationships indicated by Rödelsperger (2011), the error of the determined displacement $\sigma_{D}$ can be made dependent on the value of the SNR using the equation:

$\sigma_{D}=\frac{\lambda \cdot \sqrt{S N R+0.5}}{2 \pi \cdot S N R}$

where $S N R$ is the signal-to-noise ratio (in the linear scale) and $\lambda$ is the radar wavelength (17.4 $\mathrm{mm}$ for the IBIS-L system). This means that for all of the observed reflectors, the
Table 4 The ranges of the path length scale change $(\Delta s)$ during the experiment due to the change of the particular atmospheric conditions, assuming the stability of other parameters

\begin{tabular}{|c|c|c|c|c|}
\hline \multicolumn{5}{|l|}{ Temperature $(t)$} \\
\hline$-1.2^{\circ} \mathrm{C}$ & $29.9^{\circ} \mathrm{C}$ & & & \\
\hline$s_{\min }(\mathrm{ppm})$ & $s_{\max }(\mathrm{ppm})$ & Constant parameters & $\Delta s_{\min / \max }(\mathrm{ppm})$ & $\Delta s_{\text {range }}(\mathrm{ppm})$ \\
\hline 303.8 & 315.0 & $p=1030 \mathrm{hPa}, e=35 \%$ & 19.9 & 93.8 \\
\hline 323.7 & 428.7 & $p=1005 \mathrm{hPa}, e=100 \%$ & 113.7 & \\
\hline \multicolumn{5}{|c|}{ Atmospheric pressure $(p)$} \\
\hline Min. value & Max. value & & & \\
\hline 1004.4 hPa & $1029.3 \mathrm{hPa}$ & & & \\
\hline$s_{\min }(\mathrm{ppm})$ & $s_{\max }(\mathrm{ppm})$ & Constant parameters & $\Delta s_{\min / \max }(\mathrm{ppm})$ & $\Delta s_{\text {range }}(\mathrm{ppm})$ \\
\hline 429.5 & 435.9 & $t=30{ }^{\circ} \mathrm{C}, e=100 \%$ & 6.4 & 0.7 \\
\hline $\begin{array}{l}296.2 \\
\text { Humidity (e) }\end{array}$ & 303.3 & $t=0{ }^{\circ} \mathrm{C}, e=35 \%$ & 7.1 & \\
\hline Min. value & Max. value & & & \\
\hline $35.7 \%$ & $100.0 \%$ & & & \\
\hline$s_{\min }(\mathrm{ppm})$ & $s_{\max }(\mathrm{ppm})$ & Constant parameters & $\Delta s_{\min / \max }(\mathrm{ppm})$ & $\Delta s_{\text {range }}(\mathrm{ppm})$ \\
\hline 303.5 & 323.2 & $t=0{ }^{\circ} \mathrm{C}, p=1030 \mathrm{hPa}$ & 19.6 & 91.1 \\
\hline 318.7 & 429.5 & $t=30{ }^{\circ} \mathrm{C}, p=1005 \mathrm{hPa}$ & 110.7 & \\
\hline
\end{tabular}




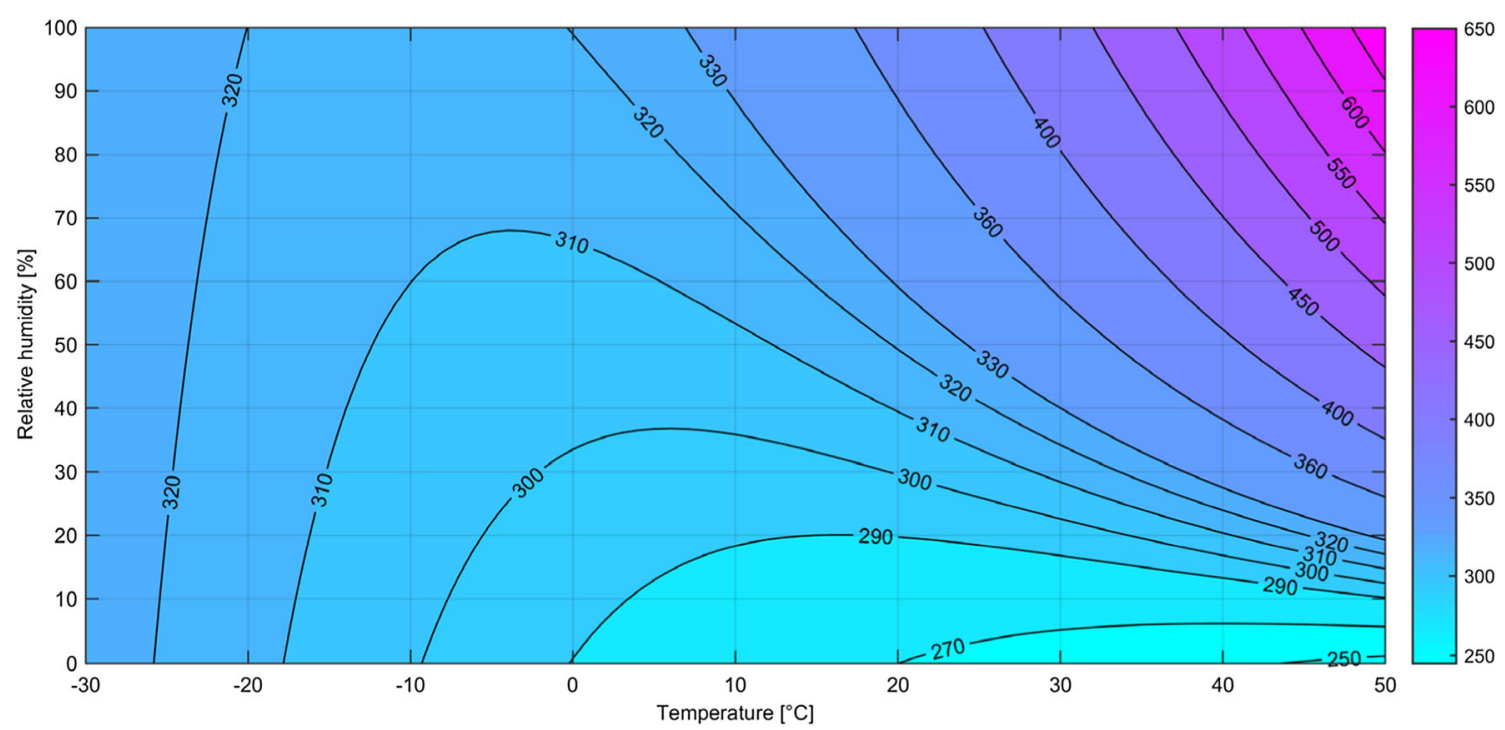

Fig. 12 Isolines of the path length scaling factor $(s)$ depending on changes in humidity and temperature (values in ppm)

displacement error due to the SNR value will not be greater than $0.5 \mathrm{~mm}$.

\section{Atmosphere variability}

Atmospheric delay for radar measurements can reach significant values. Luzi et al. (2004) state that "the uncertainty due to lack in meteorological homogeneity can be of the order some millimeters." An effective way to eliminate artificial displacements caused by changes in atmospheric conditions is to locate a stable reference point in the observed scene. Tests carried out by Gocał et al. (2013) for the IBIS-L system showed that correction of displacements based on two reference reflectors allows to obtain correct displacement values in the range of $0.05 \mathrm{~mm}$. However, in this case the stable reference reflectors were very close to the observed point (less than $20 \mathrm{~m}$ ), which is usually not possible in real conditions. Crosetto et al. (2013) state that the standard deviation of the atmospheric component is in the range from 0.7 to $1.8 \mathrm{~mm}$ at $100 \mathrm{~m}$, from 0.8 to $3.1 \mathrm{~mm}$ at $200 \mathrm{~m}$, and from 0.9 to $3.6 \mathrm{~mm}$ at $300 \mathrm{~m}$. They give the recommended maximum distance between reference reflectors as a few hundred of meters for the case of a landslide. They also note that this limitation should be particularly met for steep slopes, because of the vertical atmospheric changes stronger than horizontal ones. Moreover, Huang et al. (2017) observed the deformation of the concrete dam caused by water level changes and temperature variations from a distance of about $1000 \mathrm{~m}$ using the same radar system. Despite the possibility of adopting a stable reference point, a $20 \%$ humidity difference inside the dam's orifice (40 $\mathrm{m}$ in size) caused a 1.6-mm change of the line-ofsight distance.

Another way to eliminate the impact of atmospheric changes is to model their impact on radar measurements based on their observations at the test site. Zuo et al. (2017) provide a thorough analysis including the introduction of an atmospheric model depending on the distance to the target and local conditions of the observed object. These results show that it is possible to effectively model atmosphere influences and achieve sub-millimeter accuracy in high-precision surface monitoring.

However, in the presented work there is no possibility to observe reference points, while the flood embankment covers the entire observed scene. Moreover, the points located on its foreground may be unstable, as shown by the geodetic observations ("The geodetic observations"). In return, during the
Fig. 13 The raw observations of the displacements recorded by the radar presented with color lines for the three selected points

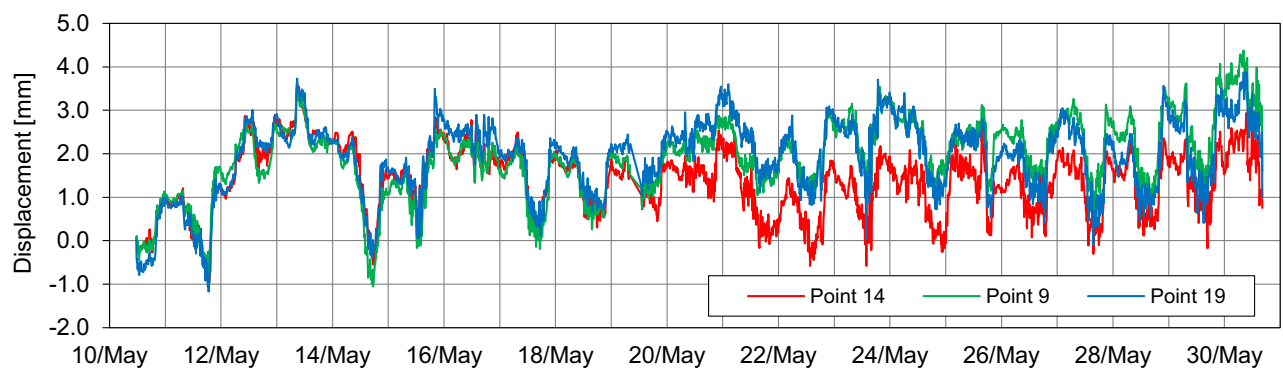


Fig. 14 A comparison of the raw radar observation of displacements (red line) and the model of atmospheric delay calculated with empirical formula (black line) for a selected point

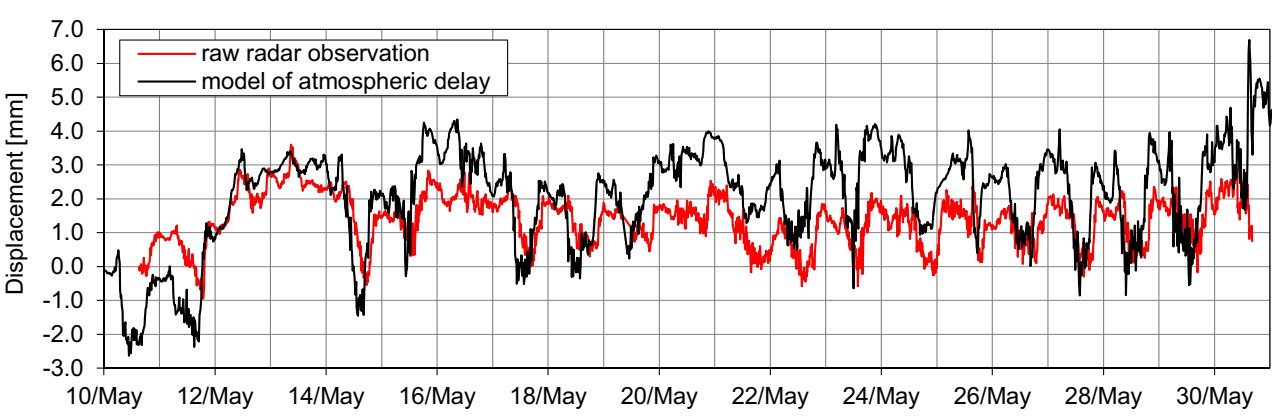

research the variable atmospheric data were acquired by the weather station, located $3 \mathrm{~m}$ above the ground, near the levee. A fully professional, high-quality automatic weather station from the Lambrecht company was used to perform measurements of all characteristic atmospheric phenomena. Those of them that are important for radar measurements, i.e., temperature, pressure, and relative humidity, are presented in Fig. 11 for the duration of the experiment. The recording of atmospheric data took place every $15 \mathrm{~min}$. The accuracy of the measurement is as follows:

- $\quad \pm 0.1{ }^{\circ} \mathrm{C}$ (for $0 \div 60{ }^{\circ} \mathrm{C}$ ), $\pm 0.2{ }^{\circ} \mathrm{C}$ (for $-40 \div 0{ }^{\circ} \mathrm{C}$ ),

- $\quad \pm 1 \mathrm{hPa}$ (for $-10 \div 60{ }^{\circ} \mathrm{C}$ ), and

- $\pm 1.5 \%$ (for $0 \div 80 \%$ ), $\pm 2 \%$ (for $80 \div 100 \%$ ).

The empirical formula given by Zebker et al. (1997) allows for calculation of the contribution to path length from the hydrostatic delay and water vapor. These effects may be approximated by

$\Delta x=7.76 \cdot 10^{-5} \int_{0}^{X} \frac{p}{T} \mathrm{~d} x+3.73 \cdot 10^{-1} \int_{0}^{X} \frac{e}{T^{2}} \mathrm{~d} x$

where $\Delta x$ is the phase shift as a change in path length, $X$ is the total path length through the atmosphere, $p$ is the atmospheric pressure in hectopascals, $T$ is the temperature in Kelvin, and $e$ is the partial pressure of water vapor in hectopascals.

Knowing the radar wavelength, the value of the shift phase has been converted to the changes in the measured distance caused by variable atmospheric conditions and is shown in Fig. 11 as a continuous line. The calculations were made for point no. 14 as a sample point.

Considering the significant values of the artificial displacements determined in Fig. 11, the impact of the variable atmosphere parameters on the radar measurements was analyzed for the research period. The range of changes is considered in Table 4. For these ranges, the values of the factor $s$ scaling the measured distance were calculated (in ppm). For each atmosphere parameter, the conditions at which $s$ takes the minimum and maximum value have been determined. The calculations were carried out for the ranges of change in the atmosphere parameters that occurred during the experiment.

For example, a change in temperature between -1.2 and $29.9{ }^{\circ} \mathrm{C}$ generates the change of the distance scaling factor $\Delta s_{\min }=19.9 \mathrm{ppm}$ (for $p=1030 \mathrm{hPa}=$ const and $e=35 \%=$ const) and $\Delta s_{\max }=113.7 \mathrm{ppm}$ (for $p=1005 \mathrm{hPa}=$ const and $e=100 \%=$ const). The presented results indicate that the factor, which alters the scale of the measured path length to the least extent, is the change of the atmospheric pressure. During the research, this impact was never greater than $7.1 \mathrm{ppm}$. This means a change of $1.35 \mathrm{~mm}$ for the largest radar-target-radar distance, which equals $190 \mathrm{~m}$ for the experiment. However, taking into account the values of the expected displacements of the flood embankment, even this factor should be included. In this light, the need to consider the variability of the remaining parameters is obvious, while its absence may cause a path length scale reaching $113.7 \mathrm{ppm}$, which translates into a
Fig. 15 The displacements of the three selected points after the atmospheric and geometric correction presented with color lines

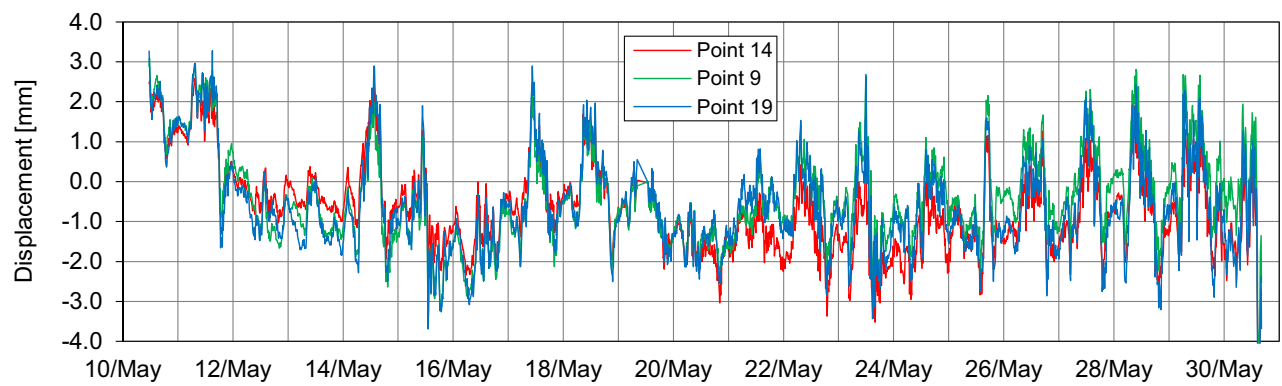




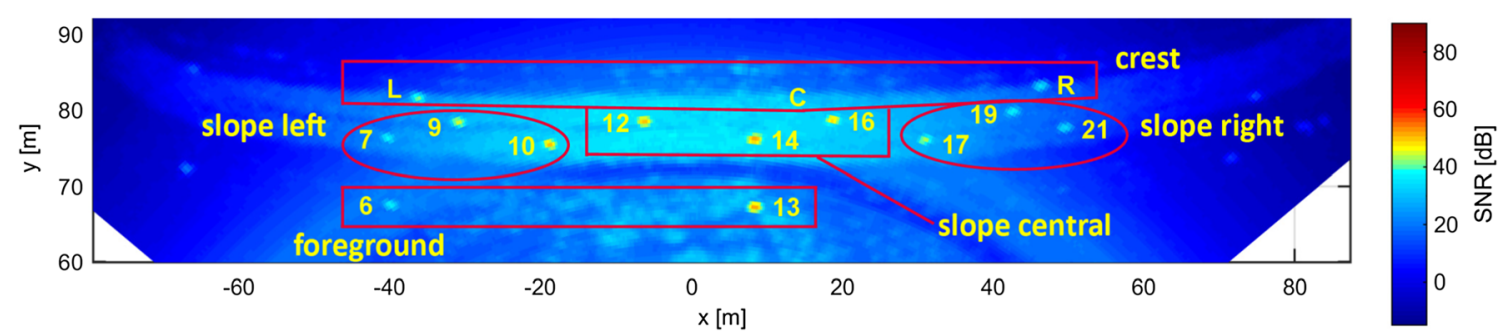

Fig. 16 The division of the points into five groups according to their location on the background of the SNR distribution

change of distance equal to $21.60 \mathrm{~mm}$ for the longest observed distance.

After indicating the temperature and humidity as the factors that most significantly affect the scale change, a graph of the influence of these values on the scaling factor was prepared for a constant pressure value assumed as $p=1020 \mathrm{hPa}=$ const (Fig. 12). Formula (7) was used to prepare the graph, assuming the distance as $1000 \mathrm{~m}$ and obtaining values of scaling factor in parts per million (ppm). As an example of the chart interpretation, a change in humidity from 30 to $90 \%$ at a constant temperature of $20{ }^{\circ} \mathrm{C}$ changes the path length scale by approximately $60 \mathrm{ppm}$.

Taking into account the largest effect of temperature and humidity (Table 4) and the largest measurement inaccuracy for the parameter of humidity, the impact of this quantity on the displacement measurement was calculated. Based on Fig. 12, it can be seen that, e.g., for a constant pressure of $1020 \mathrm{hPa}$ and a constant temperature of $30^{\circ} \mathrm{C}$, the humidity measurement uncertainty of $\pm 1.5 \%$ results in a change of the scale factor of $\pm 2.5 \mathrm{ppm}$. For the longest distance observed in this experiment, this means $\pm 0.48 \mathrm{~mm}$.

\section{The results of the field experiment}

Radar imaging is the basis for generating interferograms, which are used to determine the phase difference values recorded for all pixels between consecutive images. Phase differences are converted into displacement values, and they are calculated relative to the time of observation beginning.

Figure 13 shows the displacement graphs for three sample points selected from fourteen. The daily trend is visible, which indicates the effect of atmospheric factors with similar variability throughout the day. Further processing requires therefore to take into account the changing properties of the radar wave propagation medium.

Afterwards, the values of the displacements recorded as raw observations were compiled with the values calculated on the basis of the theoretical model of the atmospheric delay (Fig. 14). Calculations were made based on the recording of atmosphere parameters (Fig. 11) and formula (7). The analysis was carried out consistently for point no. 14 . The similarity of the course of both lines is clearly visible, which indicates a significant impact of the changes in the atmosphere on the observations. However, there are noticeable time intervals in which the observed and modeled movements are shifted relative to each other. The actual displacement of the observed embankment, affected by force changes like the water level changes, should be sought in these places.

Figure 15 shows the effect of atmospheric reduction for the radar observations. The corrected values of displacements were calculated as the difference between raw radar observation and the model of atmospheric delay. In addition, a geometric correction was introduced, which means that radial displacements (towards the radar) were converted into the displacements perpendicular to the embankment (in the expected direction of the movement).

The graphs were made only for the selected points 9, 14, and 19 (similar to Fig. 13), but for the remaining points the nature of the observed phenomena is similar. Despite taking into account the model of the atmospheric changes, some daily irregularities of the course are still visible on the graphs. Probably, they are the result of the lack of accurate information on the local state of the atmosphere. However, in the obtained results the reaction of the embankment to the induced load can be found out, especially by its time confrontation with the water level affecting the embankment.

In order to eliminate irregularities from the course of the daily displacement, observations for the daily periods were averaged, assuming a similar variation of atmospheric conditions in these intervals. In addition, the observed points were divided into five groups due to their location: crest, slope left, slope central, slope right, and foreground (Fig. 16).

Figure 17 presents the daily displacements of the points divided into five groups that may be subject to similar influences due to their location on the embankment. The black dotted line indicates the mean value of the displacements for all of the observed points. Negative movements, i.e., towards the outside of the embankment, are noticeable for all points, what is consistent with the predictions. Displacements for points 7 and 21 are notably visible. In the vicinity of their location places, the failures of the embankment structure were noticed, which for point 7 were revealed in the form of a weak 

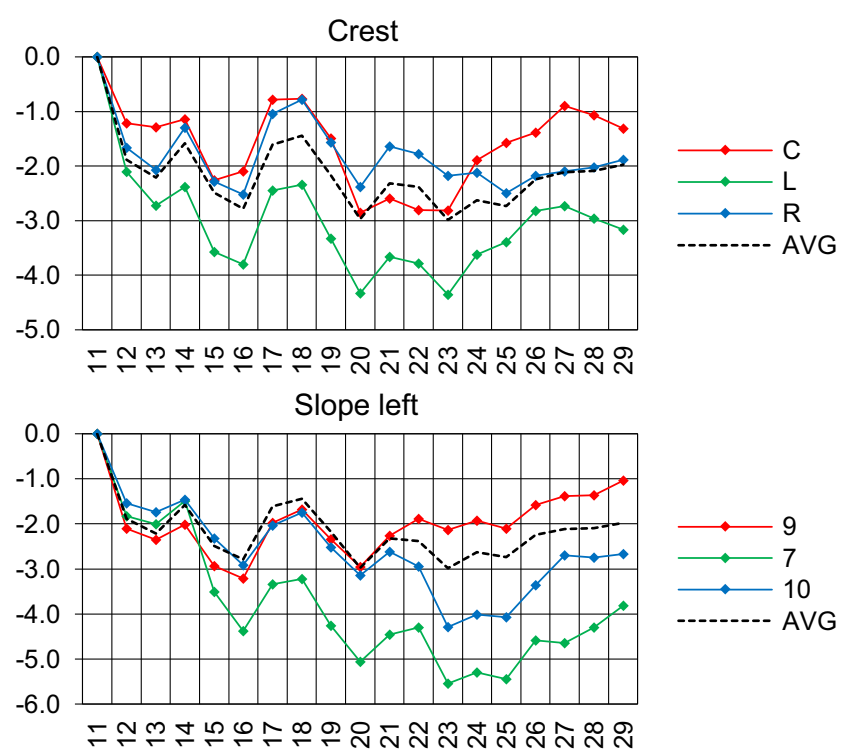

Slope central
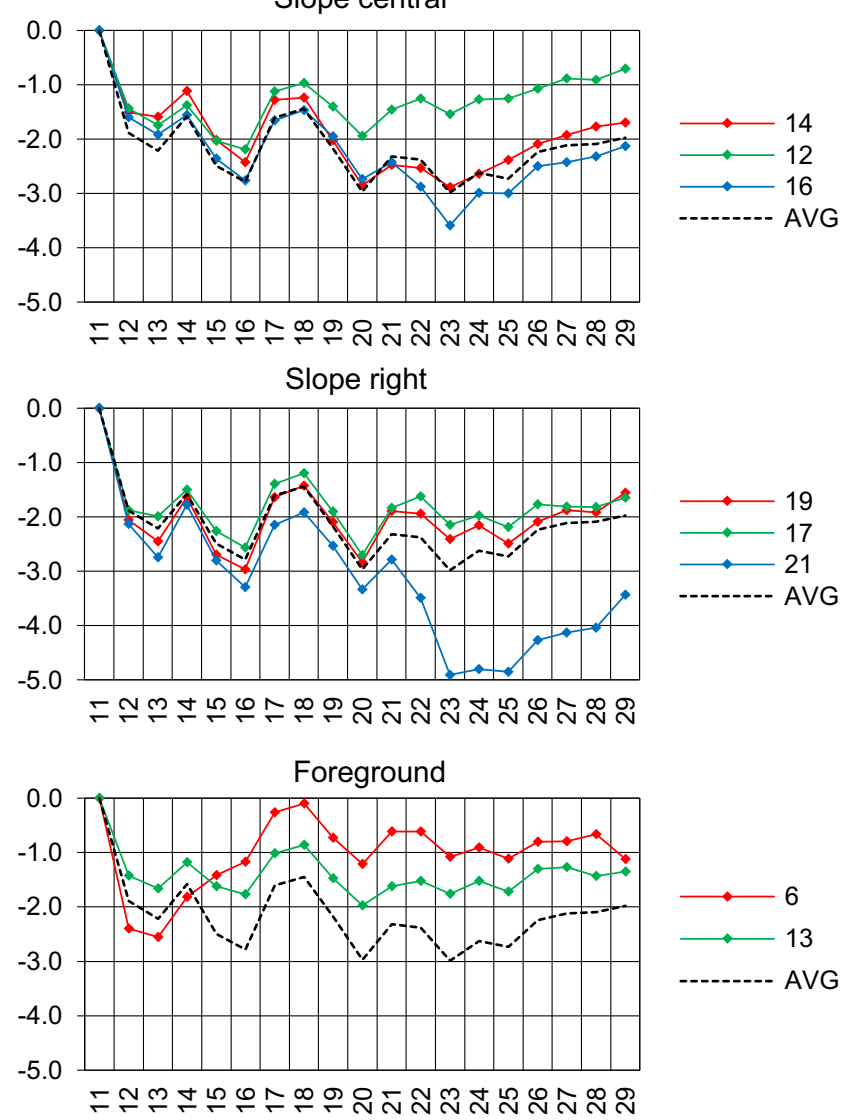

Fig. 17 The daily displacements of the observed points presented with color lines in relation to the average value given in the black dotted line (horizontal axis: day of May, vertical axis: displacement (mm))

water leakage. On the other hand, the points on the foreground $(6,13)$ seem rather stable.

Figure 18 summarizes the average displacement graphs for all 5 groups of points and presents them on the background of a variable water level during the experiment. All points located on the embankment body show similar displacements at the level of single millimeters. The movement occurs in the horizontal direction generally in accordance with the change in the horizontal component of the water pressure depending on the water level in the reservoir. Moreover, it is possible to perceive smaller horizontal displacement values on May 17-18, which corresponds to the lower water level. This may indicate that in specific cases earth-filled structures may behave to some extent like elastic structures.

\section{A comparison of surveying and radar observations}

During the experiment, surveying and radar measurements were carried out completely independently. Both techniques use a different range of electromagnetic waves to perform observations. Although the method of conducting surveying and radar observations is quite different, especially in terms of observation continuity, a comparison of displacements obtained with these two techniques was made for periods in which it was possible. For this purpose, the surveying network measurements that were carried out during the continuous radar observations were selected. Figure 5 shows that this opportunity exists for interval 3 and interval 4 . It is important that during these observations the water level changed significantly, which could have caused identifiable embankment displacements.

The set of points subject to geodetic measurements and observed by radar is relatively small. These points have to be equipped with a surveying prism and covered by the radar observation range. Their number is nine. In Table 5 , the values of their displacements in a direction perpendicular to the embankment surface are summarized. They are marked as $d_{1}$ (values from surveying) and $d_{2}$ (values from radar measurement). They are also presented in Fig. 19. In addition, in Table 5 the values of differences and averages between the methods were calculated, which will be used for further analysis.

The displacement values for the surveying were calculated on the basis of the differences in the coordinates of the surveying network points originating from the adjustment of the three measurements, which each time included testing the stability of the reference points. Negative values are dominant, as evidenced by the average displacement value of approximately $-0.4 \mathrm{~mm}$. Negative values, at the level of a few tenths of a millimeter, can be indicated for the radar observations. In the case of radar observations, the displacement values were averaged for hours 08:00-15:00 for the 3 days of May, in 
Fig. 18 The daily displacements averaged for all point groups in relation to the average value given in the black dashed line, expressed on the background of the water level

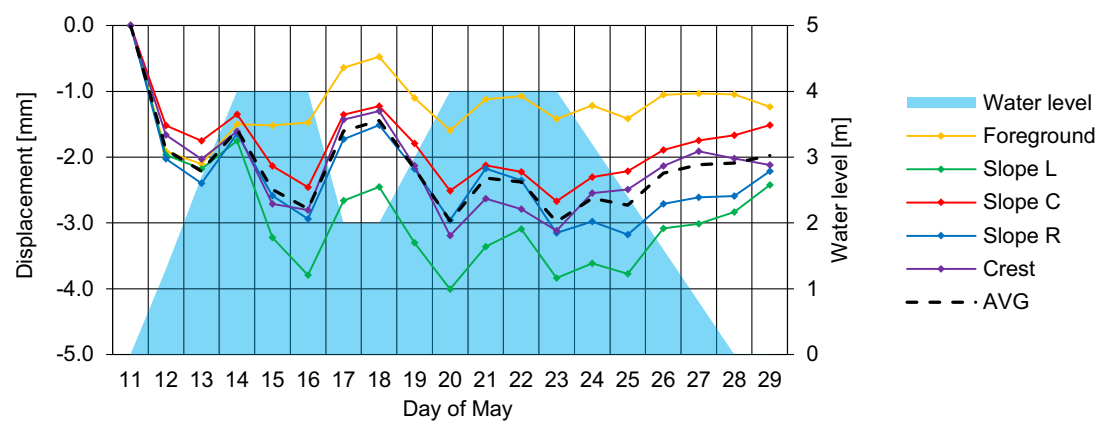

which surveying was performed. This time interval corresponds to the hours at which surveying was carried out.

Particular attention should be paid to points 7 and 21, for which relatively large displacements were found on the basis of radar observation as the possible result of embankment failures. The values of these displacements were confirmed by surveying: the highest displacement values in interval 4 were observed exactly for these points.

However, in a few cases, discrepancies between results are noticeable, e.g., for points 7, 9, 10, and 12. Displacement values determined by radar are negative ( 7 and 10$)$ or positive (9 and 12). It is worth noting that points 7 and 10 are located lower $(1 / 3$ of $\mathrm{H})$ than points 9 and $12(2 / 3$ of $\mathrm{H})$. These results indicate that the behavior of this fragment of the levee due to a change in water level was dependent on the embankment height. Therefore, the reason of the discrepancies should be rather sought in the error of geodetic measurement, which was carried out once during the measurement of the surveying network (in contrary to the continuous radar measurement).
Because of the possibility of measurement disturbances these observations may be treated as outliers.

Based on the above findings, the Bland-Altman plot (Bland and Altman 1986) was used to assess the compatibility between the results. This method is applied to evaluate the agreement among two different instruments or two measurements techniques. It is based on the fact that a high correlation between the two methods does not necessarily mean good agreement between the methods and may be due to the wide sample spread.

For each pair of observations in the sample the Cartesian coordinates are calculated according to the formula:

$d(x, y)=\left(\frac{d_{1}+d_{2}}{2}, d_{1}-d_{2}\right)$

i.e., based on the mean and difference between observations of the same quantity (Table 5). The values of $d(x, y)$ are included in Fig. 20.
Table 5 The displacement values for the points covered by the simultaneous surveying and radar observations with their differences and averages in intervals 3 and 4 (all values in $\mathrm{mm}$ ). Additionally, at the bottom of the table, calculations have been made that will be used to analyze agreement between methods using the Bland-Altman plot

\begin{tabular}{|c|c|c|c|c|c|c|c|c|}
\hline \multirow[b]{2}{*}{ Point no. } & \multicolumn{2}{|c|}{ Surveying $\left(d_{1}\right)$} & \multicolumn{2}{|c|}{$\operatorname{Radar}\left(d_{2}\right)$} & \multicolumn{2}{|c|}{ Difference $\Delta$} & \multicolumn{2}{|c|}{ Average } \\
\hline & Int. 3 & Int. 4 & Int. 3 & Int. 4 & Int. 3 & Int. 4 & Int. 3 & Int. 4 \\
\hline 7 & -0.80 & -2.02 & -1.05 & -1.53 & 0.25 & -0.49 & -0.92 & -1.78 \\
\hline 9 & 0.20 & -0.05 & -0.30 & 1.36 & 0.50 & -1.41 & -0.05 & 0.65 \\
\hline 10 & -0.72 & -0.12 & -0.16 & -1.84 & -0.56 & 1.72 & -0.44 & -0.98 \\
\hline 12 & -1.72 & 0.84 & -0.01 & 0.80 & -1.71 & 0.04 & -0.86 & 0.82 \\
\hline 14 & -0.64 & -0.24 & -0.08 & -0.53 & -0.56 & 0.29 & -0.36 & -0.38 \\
\hline 16 & -0.64 & -0.27 & -0.31 & -0.87 & -0.33 & 0.60 & -0.47 & -0.57 \\
\hline 17 & 0.44 & -0.34 & 0.29 & 0.44 & 0.15 & -0.78 & 0.37 & 0.05 \\
\hline 19 & 0.44 & -0.38 & 0.06 & 0.74 & 0.38 & -1.12 & 0.25 & 0.18 \\
\hline 21 & -0.50 & -1.42 & -0.09 & -1.46 & -0.41 & 0.04 & -0.30 & -1.44 \\
\hline Mean & -0.44 & -0.44 & -0.18 & -0.32 & -0.26 & -0.12 & -0.31 & -0.38 \\
\hline \multicolumn{5}{|c|}{ Standard deviation (SD) } & 0.68 & 0.90 & & \\
\hline \multicolumn{5}{|c|}{ $\pm 1.96 \times \mathrm{SD}$} & \pm 1.34 & \pm 1.77 & & \\
\hline \multicolumn{5}{|c|}{ Upper limit } & 1.08 & 1.65 & & \\
\hline \multicolumn{5}{|c|}{ Lower limit } & -1.59 & -1.89 & & \\
\hline
\end{tabular}




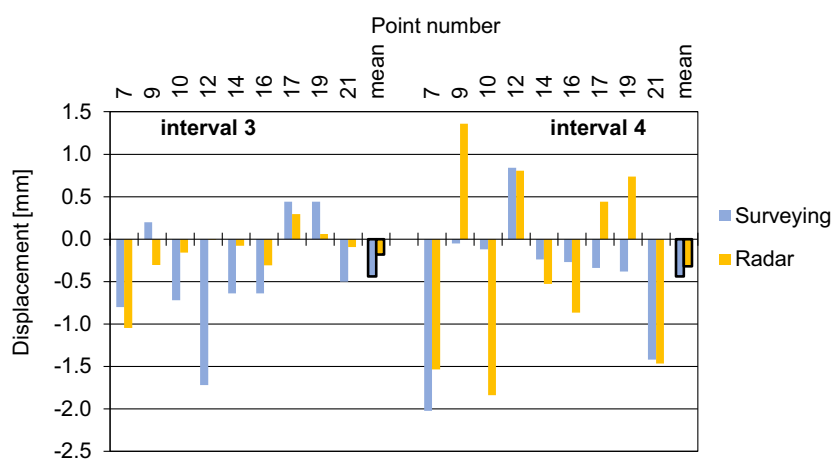

Fig. 19 Displacements $d_{1}$ and $d_{2}$ together with their mean values (bars marked with a black frame)

If the mean difference differs significantly from zero on the basis of, e.g., a 1-sample $t$ test, this indicates the presence of fixed bias between methods. For both analyzed intervals the difference from zero is considered to be not statistically significant at the $95 \%$ confidence interval.

In the Bland-Altman plot the $95 \%$ limit of agreement is usually calculated as follows: mean difference $\pm 1.96 \times$ standard deviation of the differences (Bland and Altman 1986). On this basis, upper and lower limit values for both intervals were calculated in Table 5 and presented in Fig. 20.

In the presented case, the majority of the differences in samples are within the limits of agreements, except two values, which slightly lie beyond the limits. Therefore, based on Bland-Altman's limits of agreements, these two measurement methods could be used interchangeably.

\section{Conclusions}

Conducting the flood embankment monitoring requires proper planning. While surveying is rather a common task applied in such kind of research, the use of ground-based radar interferometry requires several factors to be considered. It is necessary to choose the appropriate imaging resolution that takes into account the limitations of the observation space. In addition, achieving high accuracy requires marking of the tested structure using radar reflectors to obtain a high signal-to-noise ratio. It has also been shown that the variability of atmosphere parameters, especially temperature and humidity, is an extremely important factor, especially when it is not possible to adopt a stable reference point.

The results of the conducted measurements allow to detect the reaction of the embankment to the external loads. In the case of long-term monitoring, the movement may be caused by atmospheric factors (e.g., soil freezing), vehicles moving on the embankment body or the vestigial subsidence of the newly built embankment, and also by the frost heave of the soils used for the construction of the embankments. On the other hand, in the case of changing water level, the relation between embankment soaking and the directions of its movement can be noticed. Horizontal displacements indicate that in some cases earth-filled embankments may behave to some extent like elastic structures. The movement occurs in the horizontal direction generally in accordance with the change of the water pressure depending on the water level.

The conducted research allowed for finding high similarity between the results of the surveying and radar observations. For the time intervals in which it was possible to compare both techniques, the differences of displacements, resulting from the variable water level, were analyzed. The differences between the results of both methods reach significant values, which may be due to many factors: inaccuracy of measuring devices or inaccuracy of modeling the impact of atmospheric changes. Nevertheless, the movement trend is consistent for both methods. This was evidenced particularly by the compatibility of the considerable displacements detected for the points located in the area of presumed embankment failure. In addition, the differences are within the limits of agreements determined on the basis of the Bland-Altman plot, which means that these two measurement methods could be used interchangeably.
Fig. 20 The Bland-Altman plot for differences $\Delta$ for intervals 3 and 4 . The dots stand for the $d(x$, $y$ ) values, and the horizontal lines indicate the upper and lower limits of agreement

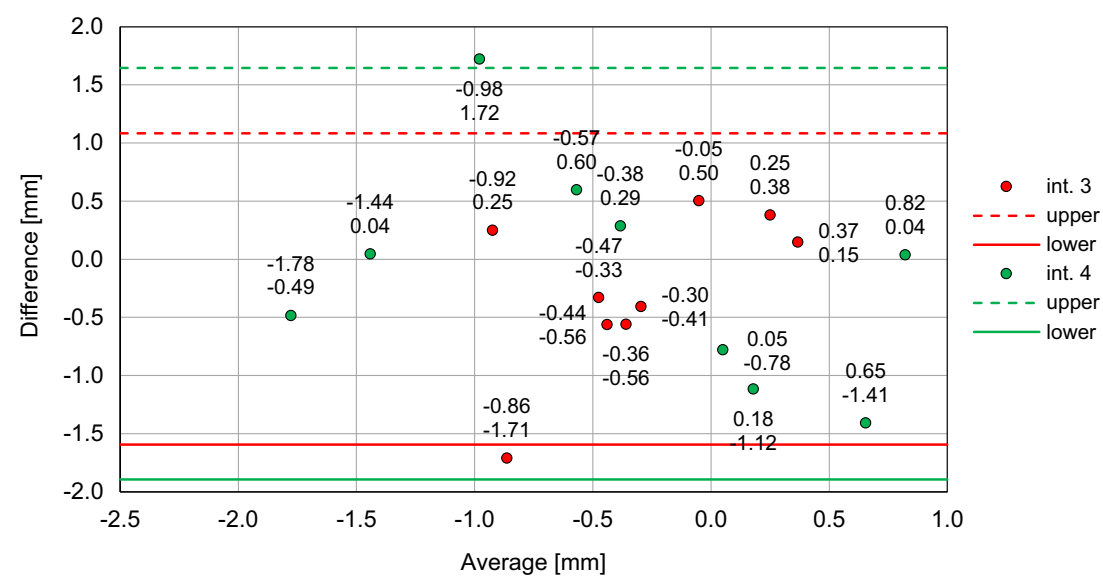


Acknowledgments The analysis and processing of the observations were conducted under the research subvention of AGH University of Science and Technology No. 16.16.150.545 in 2020.

Open Access This article is licensed under a Creative Commons Attribution 4.0 International License, which permits use, sharing, adaptation, distribution and reproduction in any medium or format, as long as you give appropriate credit to the original author(s) and the source, provide a link to the Creative Commons licence, and indicate if changes were made. The images or other third party material in this article are included in the article's Creative Commons licence, unless indicated otherwise in a credit line to the material. If material is not included in the article's Creative Commons licence and your intended use is not permitted by statutory regulation or exceeds the permitted use, you will need to obtain permission directly from the copyright holder. To view a copy of this licence, visit http://creativecommons.org/licenses/by/4.0/.

\section{References}

Bland JM, Altman DG (1986) Statistical methods for assessing agreement between two methods of clinical measurement. Lancet 327(8476):307-310. https://doi.org/10.1016/S0140-6736(86) 90837-8

Bozzano F, Cipriani I, Mazzanti P, Prestininzi A (2011) Displacement patterns of a landslide affected by human activities: insights from ground-based InSAR monitoring. Nat Hazards 59(3):1377-1396. https://doi.org/10.1007/s11069-011-9840-6

Castagnetti C, Bertacchini E, Corsini A, Capra A (2013) Multi-sensors integrated system for landslide monitoring: critical issues in system setup and data management. Eur J Remote Sens 46(1):104-124. https://doi.org/10.5721/EuJRS20134607

Crosetto M, Gili JA, Monserrat O, Cuevas-González M, Corominas J, Serral D (2013) Interferometric SAR monitoring of the Vallcebre landslide (Spain) using corner reflectors. Nat Hazards Earth Syst Sci 13(4):923-933. https://doi.org/10.5194/nhess-13-923-2013

Dardanelli G, Pipitone C (2017) Hydraulic models and finite elements for monitoring of an earth dam, by using GNSS techniques. Period Polytech-Civ 61(3):421-433. https://doi.org/10.3311/PPci.8217

Di Pasquale A, Corsetti M, Guccione P, Lugli A, Nicoletti M, Nico G, Zonno A (2013) Ground-based SAR interferometry as a supporting tool in natural and man-made disaster. In: Lasaponara R, Masini N, Biscione M (eds) Proc. of the 33th EARSeL Symposium, Matera, Italy, pp 173-186

Ferhat G, Malet JP, Puissant A, Caubet D, Huber E (2017) Geodetic monitoring of the Adroit landslide, Barcelonnette, French Southern Alps. In: Proc. of the 7th International Conference on Engineering Surveying INGEO 2017, Lisbon, Portugal

Ferrigno F, Gigli G, Fanti R, Intrieri E, Casagli N (2017) GB-InSAR monitoring and observational method for landslide emergency management: the Montaguto earthflow (AV, Italy). Nat Hazards Earth Syst Sci 17(6):845-860. https://doi.org/10.5194/nhess-17-845-2017

Frukacz M, Wieser A (2017) Terrestrial radar interferometry with objects observed through protection fences. In: Lienhart W (ed) Proc. of the 18 Internationaler Ingenieurvermessungskurs, Graz, Austria, pp 277-283

Gentile C, Bernardini G (2010) An interferometric radar for non-contact measurement of deflections on civil engineering structures: laboratory and full-scale tests. Struct Infrastruct E 6(5):521-534. https:// doi.org/10.1080/15732470903068557

Gikas V, Sakellariou M (2008) Settlement analysis of the Mornos earth dam (Greece): evidence from numerical modeling and geodetic monitoring. Eng Struct 30(11):3074-3081. https://doi.org/10.1016/ j.engstruct.2008.03.019
Gocał J, Ortyl Ł, Owerko T, Kuras P, Kocierz R, Ćwiąkała P, Puniach E, Sukta O, Bałut A (2013) Determination of displacement and vibrations of engineering structures using ground-based radar interferometry. AGH University of Science and Technology Press, Kraków

Huang Q, Luzi G, Monserrat O, Crosetto M (2017) Ground-based synthetic aperture radar interferometry for deformation monitoring: a case study at Geheyan Dam, China. J Appl Remote Sens 11(3): 036030. https://doi.org/10.1117/1.JRS.11.036030

Intrieri E, Gigli G, Mugnai F, Fanti R, Casagli N (2012) Design and implementation of a landslide early warning system. Eng Geol 147:124-136. https://doi.org/10.1016/j.enggeo.2012.07.017

ISO (2015) Geotechnical investigation and testing - Geotechnical monitoring by field instrumentation - part 1: general rules (ISO Standard No. 18674-1)

Jafari M, Schwieger V, Saba H (2015) Dynamic approachs for system identification applied to deformation study of the dams. Acta Geod Geophys 50(2):187-206. https://doi.org/10.1007/s40328-014-0091-

Kuras P, Ortyl $Ł$ (2014) Selected geometric aspects of planning and analysis of measurement results of tall building structures using interferometric radar. Geomatics and Environmental Engineering 8(3):77-91. https://doi.org/10.7494/geom.2014.8.3.77

Kuras P, Ortyl Ł, Owerko T, Borecka A (2018) Geodetic monitoring of earth-filled flood embankment subjected to variable loads. Reports on Geodesy and Geoinformatics 106(1):9-18. https://doi.org/10. 2478/rgg-2018-0009

Lienhart W, Ehrhart M, Grick M (2017) High frequent total station measurements for the monitoring of bridge vibrations. Journal of Applied Geodesy, 11(1):1-8. https://doi.org/10.1515/jag-20160028,1

Luzi G, Pieraccini M, Mecatti D, Noferini L, Guidi G, Moia F, Atzeni C (2004) Ground-based radar interferometry for landslides monitoring: atmospheric and instrumental decorrelation sources on experimental data. IEEE T Geosci Remote 42(11):2454-2466. https://doi. org/10.1109/TGRS.2004.836792

Moellmann A, Vermeer PA, Huber M (2011) A probabilistic finite element analysis of embankment stability under transient seepage conditions. Georisk 5(2):110-119. https://doi.org/10.1080/ 17499511003630520

Monserrat O, Crosetto M, Luzi G (2014) A review of ground-based SAR interferometry for deformation measurement. ISPRS. J Photogramm 93:40-48. https://doi.org/10.1016/j.isprsjprs.2014.04.001

Mujumdar PP (2001) Flood wave propagation. Resonance 6(5):66-73. https://doi.org/10.1007/BF02839085

Owerko T, Ortyl Ł, Kocierz R, Kuras P, Salamak M (2012) Investigation of displacements of road bridges under test loads using radar interferometry - case study. In: Biondini F, Frangopol DM (eds) Proc. of the 6th International IABMAS Conference, CRC Press, Stresa, Italy, pp 181-188

Pieraccini M, Luzi G, Atzeni C (2001) Terrain mapping by ground-based interferometric radar. IEEE T Geosci Remote 39(10):2176-2181. https://doi.org/10.1109/36.957280

Piniotis G, Gikas V, Mpimis T, Perakis H (2016) Deck and cable dynamic testing of a single-span bridge using radar interferometry and videometry measurements. Journal of Applied Geodesy 10(1):8794. https://doi.org/10.1515/jag-2015-0030

Pipitone C, Maltese A, Dardanelli G, Lo Brutto M, La Loggia G (2018) Monitoring water surface and level of a reservoir using different remote sensing approaches and comparison with dam displacements evaluated via GNSS. Remote Sens-Basel 10(1):71. https://doi.org/ 10.3390/rs 10010071

Pirotti F, Guarnieri A, Masiero A, Vettore A (2015) Preface to the special issue: the role of geomatics in hydrogeological risk. Geomat Nat Haz Risk 6(5-7):357-361. https://doi.org/10.1080/19475705.2014. 984248 
Qi Y, Wang Y, Yang X, Li H (2015) Application of microwave imaging in regional deformation monitoring using ground based SAR. In: Proc. of the 5th Asia-Pacific Conference on Synthetic Aperture Radar (APSAR), IEEE, Singapore, Singapore, pp 728-732. https://doi.org/10.1109/APSAR.2015.7306309

Rödelsperger S (2011) real-time processing of ground based synthetic aperture radar (GB-SAR) measurements (no. 33). Technische Universität Darmstadt, Fachbereich Bauingenieurwesen und Geodäsie

Serrano-Juan A, Vázquez-Suñè E, Monserrat $O$, Crosetto $M$, Hoffmann C, Ledesma A, Criollo R, Pujades E, Velasco V, Garcia-Gil A, Alcaraz M (2016) Gb-SAR interferometry displacement measurements during dewatering in construction works. Case of La Sagrera railway station in Barcelona, Spain. Eng Geol 205:104-115. https:// doi.org/10.1016/j.enggeo.2016.02.014
Stanisz J, Borecka A, Pilecki Z, Kaczmarczyk R (2017) Numerical simulation of pore pressure changes in levee under flood conditions. E3S Web of Conferences 24:03002. https://doi.org/10.1051/ e3sconf $/ 20172403002$

Xing C, Yu ZQ, Zhou X, Wang P (2014) Research on the testing methods for IBIS-S system. IOP Conf Ser Earth Environ Sci 17:012263

Zebker HA, Rosen PA, Hensley S (1997) Atmospheric effects in interferometric synthetic aperture radar surface deformation and topographic maps. J Geophys Res-Sol Ea 102(B4):7547-7563. https:// doi.org/10.1029/96JB03804

Zuo X, Yu H, Zi C, Xu X, Wang L, Liu H (2017) Meteorological correction model of IBIS-L system in the slope deformation monitoring. Intell Autom Soft Co 2017:1-8. https://doi.org/10.1080/ 10798587.2016.1267240 